\title{
Blood pressure overshoot after tilt reversal in patients with familial amyloidotic polyneuropathy
}

\author{
Konen Obayashi $^{1,4}$, Rolf Hörnsten ${ }^{2}$, Urban Wiklund ${ }^{3}$, Marcus Karlsson ${ }^{3}$, Sadahisa Okamoto ${ }^{1}$, Yukio Ando ${ }^{4}$ \\ and Ole B Suhr ${ }^{1}$
}

The pathophysiology of the hemodynamic responses to postural stress in familial amyloidotic polyneuropathy (FAP) remains to be elucidated. The aim of the study was to evaluate hemodynamic responses after tilt reversal in FAP. Systolic blood pressure (BP) and heart rate variability (HRV) were analyzed in the baseline, $70^{\circ}$ upright position, and after tilt reversal in 15 FAP patients and 14 healthy controls. Beat-to-beat BP was recorded with a Finapres device. Maximum systolic BP after tilt reversal was increased with $22 \pm 13 \mathrm{~mm} \mathrm{Hg}$ in FAP patients as compared with baseline (BP overshoot), whereas controls showed a significantly lower BP overshoot $(8 \pm 6 \mathrm{~mm} \mathrm{Hg}, P<0.001)$. In all states, total spectral power and the power of the low and high frequency components were all significantly lower than those of the controls $(P<0.01)$. In a linear regression analysis adjusted for age, we found a significant inverse relation between BP overshoot and HRV (total spectral power, power of the low-frequency and high-frequency components) in all three states (standardized $\beta$ between -0.74 to $-0.53, P<0.01$ ). Five FAP patients presented a trial arrhythmia precluding HRV analysis: four of those presented BP overshoots $\geqslant 12 \mathrm{~mm} \mathrm{Hg}$. BP overshoot may be a marker to assess the progression of cardiac autonomic dysfunction, especially as heart arrhythmia in many FAP patients prevent HRV analysis. In addition, assessment of the post-tilt BP reaction points to possible treatment modalities for orthostatic hypotension at least in the early stages of the disease.

Hypertension Research (2011) 34, 133-138; doi:10.1038/hr.2010.181; published online 7 October 2010

Keywords: autonomic nervous system; blood pressure; familial amyloidotic polyneuropathy (FAP); heart rate variability (HRV); transthyretin (TTR)

\section{INTRODUCTION}

Hereditary transthyretin amyloidosis is a heterogeneous collection of familial diseases marked by the systemic accumulation of amyloid fibrils in various organs, often including the heart and peripheral nerves. ${ }^{1,2}$ Familial amyloidotic polyneuropathy (FAP) is the most common neuropathy type of the disease. FAP is caused by an amyloidogenic transthyretin point mutation where valine is replaced by methionine at position 30 (amyloidogenic transthyretin Valine30Methionine, Val30Met). ${ }^{3}$ Sporadic families with FAP are present worldwide, with an accumulation in endemic areas in Sweden, Portugal, and Japan.

Autonomic dysfunction occurs early after onset of FAP. ${ }^{4}$ Among the various autonomic symptoms, orthostatic hypotension is one of the most serious in FAP, as the patients' daily life becomes restricted by dizziness and/or syncope. These symptoms may become life threatening as orthostatic hypotension causes transient loss of consciousness due to cerebral ischemia. The mechanism behind the disturbed hemodynamic responses has been suggested to be a parasympathetic dysfunction leading to myocardial muscarinic receptor upregulation. ${ }^{5}$
The presence of parasympathetic dysfunction in FAP has been verified by findings of markedly reduced heart rate variability (HRV). ${ }^{6-9}$ However, the pathophysiology of the hemodynamic responses to postural stress in FAP remains to be elucidated.

Head-up tilt is routinely used to assess cardiovascular function. Attention has also been focused on blood pressure (BP) changes after tilt reversal: patients with autonomic failure show an increase in BP after tilt reversal, as compared with the baseline values before head-up tilt (BP overshoot). ${ }^{10,11}$ Thus, post-tilt observations may be particularly useful to evaluate the hemodynamic basis of supine hypertension that often complicates the management of orthostatic hypotension, which is a relatively common complication: Kario et al. reported that the incidence of orthostatic hypotension was $9.5 \%$ in elderly patients with hypertension. ${ }^{12}$

BP overshoot is more pronounced in post-ganglionic disorders (pure autonomic failure) than in pre-ganglionic disorders (multiple system atrophy). ${ }^{10}$ The underlying mechanisms for the observed differences reflect the different location of the autonomic lesion in pure autonomic failure and multiple system atrophy. ${ }^{13}$ As FAP

\footnotetext{
${ }^{1}$ Department of Medicine, Umeå University Hospital, Umeå, Sweden; ${ }^{2}$ Department of Clinical Physiology, Heart Centre, Umeå University Hospital, Umeå, Sweden; ${ }^{3}$ Department of Biomedical Engineering and Informatics, Umeå University Hospital, Umeå, Sweden and ${ }^{4}$ Department of Diagnostic Medicine, Graduate School of Life Sciences, Kumamoto University, Honjo, Kumamoto, Japan

Correspondence: Dr K Obayashi, Department of Medicine, Umeå University Hospital, 1-1-1 Honjo, S-901 85 Umeå, Sweden.

E-mail: konen@fc.kuh.kumamoto-u.ac.jp

Received 2 May 2010; revised 1 July 2010; accepted 31 July 2010; published online 7 October 2010
} 
patients have both pre- and post-ganglionic autonomic disorders, ${ }^{14,15}$ our hypothesis was that they should display prominent BP overshoot. Therefore, the aim of this study was to investigate BP overshoot levels after tilt reversal in FAP patients and compare with healthy subjects, including assessment of autonomic function by analysis of HRV.

\section{METHODS}

\section{Subjects}

The study is based on 15 consecutively evaluated Swedish FAP patients ( 10 men and 5 women, mean age $60 \pm 12$ years), where the post-tilt HRV examinations were performed at Umeå University Hospital, Sweden from January 2008 to April 2009. The diagnosis was settled from a typical clinical history, the presence of axonal neuropathy, and the identification of amyloid deposits in tissue samples. In addition, genetic analysis had identified the amyloidogenic transthyretin Val30Met mutation in 14 patients and the Leu55Gln mutation in one patient. The mean duration of disease was 87 months (range 6-174 months). The age of the patients was relatively high, but this probably reflects that Swedish patients have higher age of onset (56 years) than Japanese and Portugese patients (33 years and 35 years, respectively). ${ }^{16-18}$ Intraventricular septal thickness was $15 \mathrm{~mm}$ (range 9-21 mm), where 12 patients had abnormal values (above $12 \mathrm{~mm}$ ). The left atrial diameter was $40 \mathrm{~mm}$ (range $29-55 \mathrm{~mm}$ ), and six patients had left atrial dilation (above $40 \mathrm{~mm}$ ). See Hörnsten et al. ${ }^{19}$ for details regarding echocardiographic measurements. Five patients had undergone liver transplantation, which is the only available treatment, ${ }^{20}$ and for those disease durations were calculated from the onset of symptoms until transplantation, as liver transplantation has the potential to stop the progression of FAP. As control group, we recruited 14 healthy subjects ( 6 men and 8 women, mean age $54 \pm 7$ years old) who had no medication and no symptoms of cardiovascular or autonomic disease. None of the subjects had any of the conventional risk factor for cardiovascular diseases such as smoking, hyperlipidemia and diabetes mellitus. One patient was treated with atenolol, $50 \mathrm{mg} \mathrm{day}^{-1}$ for hypertension. No patient was on medication that could effect the autonomic control on the cardiovascular system.

The study was approved by the ethical committees of Umeå University. The aims of the study and the study protocol were explained to all subjects, who then gave informed consent to participate.

\section{BP and electrocardiogram (ECG) recording}

Systolic BP was measured continuously in the left index finger using a Finapres 2300 Blood Pressure Monitor (Ohmeda, Madison, MI, USA). Blood pressure was also manually measured with a sphygmomanometer: once in the supine position and once in the upright position. A single-lead ECG was recorded and stored in a computer (sampling rate $500 \mathrm{~Hz}$ ). Respiration was recorded indirectly using impedance technique.

Continuous recordings of BP and ECG were started with the subject in the supine position with normal spontaneous breathing for $6 \mathrm{~min}$ (baseline). The recording continued for approximately $4 \mathrm{~min}$ after passive tilt to a $70^{\circ}$ upright position, where the tilt maneuver was performed within $3 \mathrm{~s}$. Patients then returned to the supine position after tilt reversal (tilt reversal state), where measurements continued for $10 \mathrm{~min}$. To avoid hydrostatic level differences during the tilt procedures, the subjects held the hand with the cuffed finger at approximately the same height as the heart throughout the recording. In the upright position, this was accomplished by placing the hand on a supportive rest. The time in which the subject was in the $70^{\circ}$ upright position was limited to $4 \mathrm{~min}$ because we wanted to avoid syncope during the test.

\section{Data analysis of systolic BP}

Beat-to-beat fluctuations in systolic BP were automatically determined and all values were carefully manually reviewed and corrected. All data presented in tables and figures were mean values of systolic and diastolic BP determined for non-overlapping 20-s segments from the baseline recording in the supine position, after tilt to the upright position, and in the tilt reversal state. Orthostatic hypotension was defined as a systolic BP decrease of $20 \mathrm{~mm} \mathrm{Hg}$ or more within $4 \mathrm{~min}$ of tilting, and BP overshoot was defined as the difference between the maximum systolic BP during the first 2 min after tilt reversal and the average systolic BP at baseline.

\section{Data analysis of ECG}

$\mathrm{R}$ waves were detected using a first-difference-based algorithm. Spurious artefacts and extra-systolic beats were identified and replaced by linear interpolation. Detected R-R intervals were transformed to an equidistantly sampled heart rate (HR) time series by cubic spline interpolation followed by resampling at $2 \mathrm{~Hz}$. Mean values of $\mathrm{HR}$ and spectral variables were determined for 2-min segments from the baseline recording in the supine position, after tilt to the upright position, and in the tilt reversal state. Power spectrum analysis was assessed on linearly de-trended HR data from different sequences by autoregressive modeling of order 30 . The total spectral power $\left(\mathrm{P}_{\text {tot }}\right)$ and the power of the low frequency (LF) $\left(\mathrm{P}_{\mathrm{LF}}: 0.04-0.15 \mathrm{~Hz}\right)$ and high frequency $(\mathrm{HF})\left(\mathrm{P}_{\mathrm{HF}}\right.$ : $0.15-0.50 \mathrm{~Hz}$ ) components, as well as the ratio between the power of the LF and HF components $\left(\mathrm{P}_{\mathrm{LF}} / \mathrm{P}_{\mathrm{HF}}\right)$ were calculated and log-transformed. All calculations were performed using the Matlab software package (Mathworks, Natick, MA, USA).

\section{Statistical analysis}

All data are expressed as group means \pm s.d. Differences between groups were analyzed by Mann-Whitney $U$ test, and comparison within groups by Wilcoxon's signed-rank test. The relation between BP overshoot and clinical features were analyzed by linear regression. Similarly, the relation between BP overshoot HRV was analyzed in a linear regression model, controlling for the well-known age-dependency in HRV. A $P$-value below 0.05 was considered statistically significant.

\section{RESULTS}

Five patients presented multifocal atrial arrhythmias that precluded HRV analysis. Therefore, 10 FAP patients and 14 controls remained for studies of BP and HRV reactions during head-up tilt and after tilt reversal.

\section{Blood pressure}

Figure 1 shows systolic and diastolic BP levels and mean HR during the examination for both patients and controls. Mean systolic BP in FAP patients was not significantly different from that of controls in both the baseline recording and after head-up tilt (Table 1). In the $70^{\circ}$ upright position, three patients showed orthostatic hypotension: two patients had atrial arrhythmia and the third was the patient who took $50 \mathrm{mg} \mathrm{day}^{-1}$ of atenolol. Patients also showed a trend to a successive increase in BP while being in the upright position.

After tilt reversal, all 10 patients showed systolic BP overshoot compared with the baseline, and 8 of 10 patients continued to increase their systolic BP until $4 \mathrm{~min}$ after tilt reversal. FAP patients presented a post-tilt overshoot also in diastolic BP (Figure 1). The level of systolic $\mathrm{BP}$ overshoot was significantly higher in patients than in controls ( $P=0.001$, Table 1). No significant relationship was found between BP overshoot and clinical features (disease duration, liver transplantation, or echocardiographic measures). The patient who took $50 \mathrm{mg} \mathrm{day}^{-1}$ of atenolol showed a BP overshoot of $12 \mathrm{~mm} \mathrm{Hg}$ and $>10 \%$ increment in $\mathrm{HR}$ in the $70^{\circ}$ upright position.

Note that four of the five FAP patients who were excluded because of atrial arrhythmia presented BP overshoots $\geqslant 12 \mathrm{~mm} \mathrm{Hg}$.

\section{HR and HRV}

There were no statistically significant differences between $\mathrm{HR}$ in patients and controls in any part of the recording (Figure 1). Mean values of HRV parameters in FAP patients and controls are shown in Table 2. All HRV variables (mean $\mathrm{P}_{\text {tot }}, \mathrm{P}_{\mathrm{LF}}, \mathrm{P}_{\mathrm{HF}}$, and $\mathrm{P}_{\mathrm{LF}} / \mathrm{P}_{\mathrm{HF}}$ ) were statistically significantly lower in patients than in controls. In all, 4 of the 10 patients and $11 / 14$ controls showed $>10 \%$ increment in HR in the $70^{\circ}$ upright position. Moreover, 6 out of 10 patients and 13/14 of controls showed $>50 \%$ increase in $\mathrm{P}_{\mathrm{LF}} / \mathrm{P}_{\mathrm{HF}}$ after tilt to the upright position. 

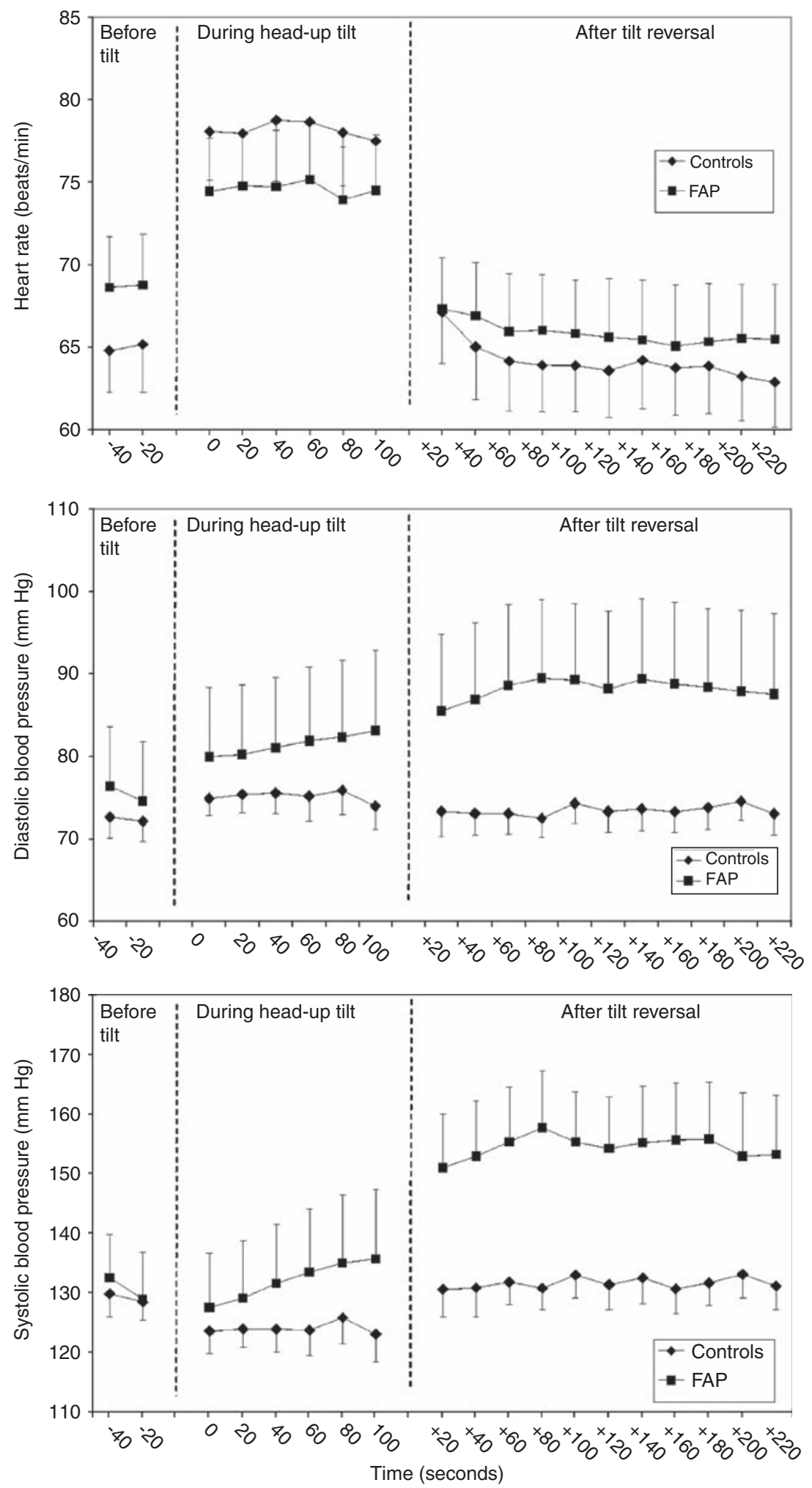

Figure 1 Changes in mean systolic and diastolic BP levels and mean HR during the test in controls and FAP patients. Values are means \pm s.e.m.

\section{Blood pressure overshoot and HRV}

Figure 2 shows examples of the relation between BP overshoot and HRV in the upright position. Similar inverse relationships between BP overshoot and HRV were found in all three states (baseline, after tilt, and in the tilt reversal state). Linear regression with adjustments for age showed that the inverse relationship was statistically significant for all spectral HRV variables (except for $\mathrm{P}_{\mathrm{LF}} / \mathrm{P}_{\mathrm{HF}}$ ) in all three states: $\mathrm{P}_{\text {tot }}$, standardized $\beta$ between -0.68 and $-0.62, P<0.005 ; \mathrm{P}_{\mathrm{LF}}$, standardized 
Table 1 Systolic blood pressure in FAP patients and controls

\begin{tabular}{lccl}
\hline & Controls $(\mathrm{n}=14)$ & FAP patients $(\mathrm{n}=10)$ & P-value \\
\cline { 2 - 4 } Systolic BP $(\mathrm{mm} \mathrm{Hg})$ & & & \\
$\quad$ Supine & $130(13)$ & $139(27)$ & 0.55 \\
Upright & $124(12)$ & $132(33)$ & 0.44 \\
After tilt reversal & $138(13)$ & $161(31)$ & 0.06 \\
BP overshoot $(\mathrm{mm} \mathrm{Hg})$ & $8(6)$ & $22(13)$ & $0.001^{*}$ \\
\hline
\end{tabular}

Abbreviation: BP, blood pressure.

Values are group means and s.d.

${ }^{*} P<0.05$.

Table 2 HRV data in FAP patients and controls

\begin{tabular}{|c|c|c|c|}
\hline & Controls $(n=14)$ & FAP patients $(\mathrm{n}=10)$ & P-value \\
\hline \multicolumn{4}{|l|}{ Supine position } \\
\hline HR (beats $\mathrm{min}^{-1}$ ) & $65.7( \pm 7.2)$ & $66.8( \pm 10.2)$ & 0.67 \\
\hline $\mathrm{P}_{\text {tot }}\left(\log \mathrm{mHz}^{2}\right)$ & $3.36( \pm 0.35)$ & $2.34( \pm 0.75)$ & $0.002 *$ \\
\hline $\mathrm{P}_{\mathrm{LF}}\left(\log \mathrm{mHz} \mathrm{z}^{2}\right)$ & $2.76( \pm 0.27)$ & $1.51( \pm 0.87)$ & $0.001 *$ \\
\hline $\mathrm{P}_{\mathrm{HF}}\left(\log \mathrm{mHz} \mathrm{z}^{2}\right)$ & $2.43( \pm 0.48)$ & $1.63( \pm 0.73)$ & $0.004 *$ \\
\hline $\log P_{L F} / P_{H F}$ & $0.34( \pm 0.38)$ & $-0.12( \pm 0.45)$ & 0.06 \\
\hline \multicolumn{4}{|l|}{ Upright position } \\
\hline HR (beats $\min ^{-1}$ ) & $78.1( \pm 9.9)$ & $74.6( \pm 10.5)$ & 0.40 \\
\hline$P_{\text {tot }}\left(\log \mathrm{mHz}^{2}\right)$ & $3.42( \pm 0.37)$ & $2.29( \pm 0.86)$ & $0.001^{*}$ \\
\hline $\mathrm{P}_{\mathrm{LF}}\left(\log \mathrm{mHz} \mathrm{z}^{2}\right)$ & $3.09( \pm 0.37)$ & $1.67( \pm 1.00)$ & $0.001^{*}$ \\
\hline $\mathrm{P}_{\mathrm{HF}}\left(\log \mathrm{mHz} \mathrm{z}^{2}\right)$ & $2.22( \pm 0.48)$ & $1.51( \pm 0.69)$ & $0.009 *$ \\
\hline $\log P_{L F} / P_{H F}$ & $0.88( \pm 0.31)$ & $0.16( \pm 0.51)$ & $0.001 *$ \\
\hline \multicolumn{4}{|l|}{ After tilt reversal } \\
\hline HR (beats $\mathrm{min}^{-1}$ ) & $67.0( \pm 9.5)$ & $67.8( \pm 10.0)$ & 0.98 \\
\hline$P_{\text {tot }}\left(\log \mathrm{mHz}^{2}\right)$ & $3.37( \pm 0.22)$ & $2.66( \pm 0.51)$ & $0.002 *$ \\
\hline $\mathrm{P}_{\mathrm{LF}}\left(\log \mathrm{mHz} \mathrm{z}^{2}\right)$ & $2.88( \pm 0.29)$ & $1.76( \pm 0.62)$ & 0.001 * \\
\hline $\mathrm{P}_{\mathrm{HF}}\left(\log \mathrm{mHz} \mathrm{z}^{2}\right)$ & $2.59( \pm 0.38)$ & $1.79( \pm 0.44)$ & $0.001 *$ \\
\hline $\log P_{L F} / P_{H F}$ & $0.29( \pm 0.36)$ & $-0.03( \pm 0.43)$ & 0.11 \\
\hline
\end{tabular}

Abbreviations: $\mathrm{HR}$, mean heart rate; $\mathrm{P}_{\mathrm{HF}}$, power of the high-frequency component $(0.15-0.50 \mathrm{~Hz})$; $P_{L F}$, power of the low-frequency component $(0.04-0.15 \mathrm{~Hz}) ; P_{\text {tot, }}$ total power, estimated by the variance; $P_{L F} / P_{H F}$, ratio between the power of the low-frequency and highfrequency components.

Values are group means and s.d.

${ }^{*} P<0.05$ $\beta$ between -0.74 and $-0.70, P<0.001 ; \mathrm{P}_{\mathrm{HF}}$, standardized $\beta$ between -0.56 and $-0.53, P<0.01 ; \mathrm{P}_{\mathrm{LF}} / \mathrm{P}_{\mathrm{HF}}$, standardized $\beta$ between -0.63 and $-0.38, P<0.07$.

\section{DISCUSSION}

We have shown that the BP overshoot reaction was present in FAP patients and had a larger magnitude as compared with that of the controls. Expectedly, HRV was significantly decreased in FAP patients, as compared with controls. Wieling et al. ${ }^{21}$ reported that healthy subjects display a spiky $18 \mathrm{~mm} \mathrm{Hg}$ systolic BP overshoot approximately $7 \mathrm{~s}$ after tilt reversal. However, the BP overshoot reaction of FAP patients was not spiky but showed a continuous increase. Thus, BP overshoot after tilt reversal in FAP appears to be an abnormal hemodynamic response. We have no experience of Valsalva tests. However, Valsalva could be considered as a short-duration test of autonomic reflexes, whereas tilt testing also could result in neurohumoral activation. If the latter actually is a major contributor to BP overshoot in FAP patients, then post tilt investigations would probably capture this phenomena better than Valsalva maneuvers.

Several factors may influence the degree of BP overshoot in FAP. The first is disturbances in cardiac autonomic function. ${ }^{8,22}$ Not only an intact sympathetic but also an intact (afferent) parasympathetic nervous system appears to be necessary for the generation of a normal circadian BP pattern. ${ }^{23}$ On the other hand, vagal function is an important component of the efferent arm of the baroreflex that regulates $\mathrm{BP}$ by changing the HR. Delahaye et al. ${ }^{5}$ disclosed that cardiac autonomic denervation in FAP results in an upregulation of myocardial muscarinic receptors without any change in cardiac $\beta$-receptor responsiveness to catecholamine. Our FAP patients presented significantly reduced HRV as compared with controls, whereas the patients' BP overshoot levels were of larger magnitude. We also found a significant inverse relationship between BP overshoot and HRV. As HRV mainly reflects vagal modulation of the sinus node, our results suggest that there is a relation between increased BP overshoot and increased both efferent and afferent vagal dysregulation.

Both controls and FAP patients increased their HR after head-up tilt, which could be due to both withdrawals of vagal input and on increased sympathetic activity. A neurohumoral response occurs within $1 \mathrm{~min}$ after tilt, consisting of an increased release of norepinephrine, which is the major neurotransmitter in the sympathetic
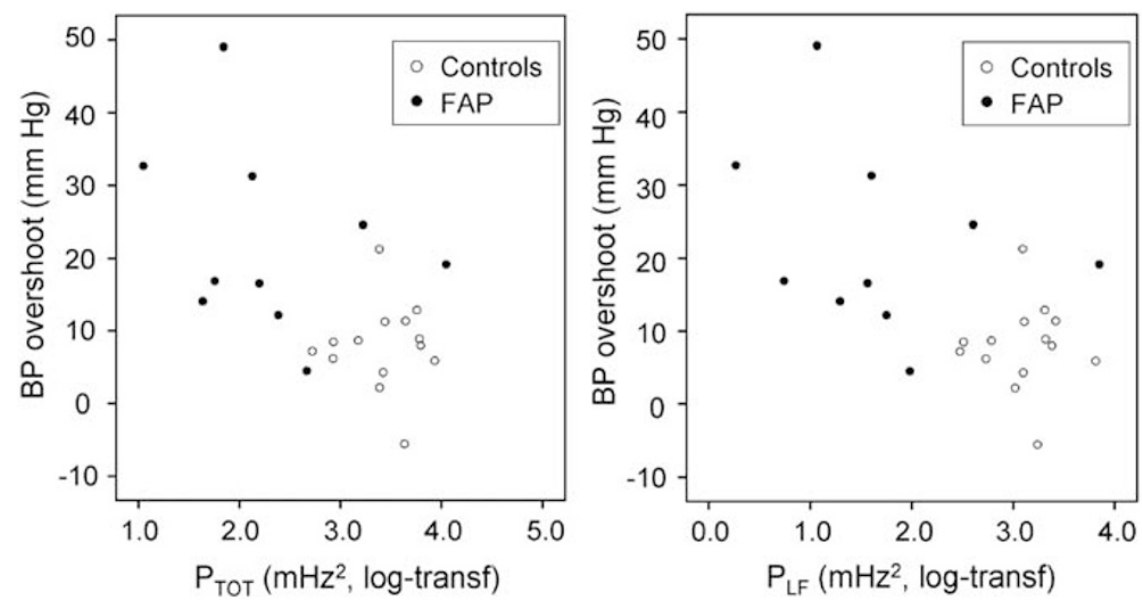

Figure 2 Relationship between HRV and BP overshoot in FAP patients in the upright position after passive head-up tilt. Left: total spectral power ( $\mathrm{P}_{\text {tot }}$ ) and $\mathrm{BP}$ overshoot. Right: power of the low-frequency component $\left(\mathrm{P}_{\mathrm{LF}}\right)$ and BP overshoot. 
system, and vasopressin. Thus, as FAP patients with pronouncedly reduced HRV are unable to further decrease vagal input, they may have a successively increased neurohumoral activation to avoid hypotension after tilt to the upright position, as suggested for patients with pure autonomic failure. ${ }^{10}$ This could also be the reason why FAP patients presented successively increased BP after tilt, whereas controls did not. Moreover, one FAP patient in this study had orthostatic hypertension. Kario ${ }^{24}$ reported that orthostatic hypertension increased neurohumoral activation.

After tilt reversal, back to the supine position, FAP patients with low HRV lack the vagal re-activation that occurs in healthy subject after tilt reversal, which could cause an imbalance in autonomic activity where sympathetic activity continues to be high during the wash-out of neurohormones. Thus, the combination of vagal dysfunction and neurohumoral overstimulation may be the main contributor to the increased BP overshoot in FAP patients.

Another factor that could have caused BP overshoot after tilt reversal is abnormal vascular regulation. In FAP patients, peripheral neuropathy progresses cephalic from the lower extremities accompanied by an increasing amount of perivascular amyloid deposits. ${ }^{1,15}$ In addition, vessel plasticity and responses to the administration of NGmonomethyl-L-arginine (L-NMMA), which is a specific inhibitor of nitric oxide, decrease with disease progression. ${ }^{25,26}$ Although the BP reaction possibly could be related to amyloid deposition around the peripheral vessels, BP overshoot has been noted in patients with pure autonomic failure without amyloid deposition or other abnormalities perivascularly. ${ }^{10,11,13}$ These findings suggest that vascular damages are not directly associated with BP overshoot in FAP.

Heart arrhythmia, especially heart block, is a well-known complication of FAP, and may contribute to the development of dizziness and/ or syncope. Indeed, 33\% of FAP patients showed arrhythmia in this study. Pacemaker treatment is frequently used, and with wider indication, as autonomic dysfunction increases the risk of life threatening Adams-Stokes attacks. ${ }^{27,28}$ Patients with frequent non-sinus beats also exhibited BP overshoot after tilt reversal. Although this finding may be related to their arrhythmia, we cannot exclude that these patients also had an abnormal cardiac autonomic regulation, but the latter could not be detected as their heart arrhythmia prevented HRV analysis.

Carvalho et al. ${ }^{23}$ reported that in contrast to various other autonomic disorders, severe autonomic failure in FAP is not associated with nocturnal hypertension. However, BP overshoot reaction was present in these patients. Our findings may have therapeutic implications for the treatment of FAP patients, as the patient treated with atenolol displayed a relatively low $\mathrm{BP}$ overshoot $(12 \mathrm{~mm} \mathrm{Hg})$ in spite of a $>10 \%$ increment in $\mathrm{HR}$ in the $70^{\circ}$ upright position. Thus, maintaining a lower HR after tilt reversal may decrease BP overshoot. However, the atenolol treated patient also showed an orthostatic BP reaction. Yamamoto et al. ${ }^{29}$ found that an abdominal band in some patients was effective to prevent post-dialytic orthostatic hypotension, without simultaneous elevation of supine systolic BP. Moreover, Gamboa et al. ${ }^{30}$ found that patients with autonomic failure have increased nitric oxide function in their vessels. Using antioxidants and/ or abdominal band therapy in combination with atenolol treatment may improve both orthostatic hypotension and BP overshoot after tilt reversal in FAP patients.

A limitation of the study is that the post-tilt changes in BP were only measured with the Finapres device. Although the absolute values of BP in general may be different from manually measured values, this device has been reported to accurately track differences in BP from a baseline level, ${ }^{31}$ which was the main focus in our study. Data were collected during clinical investigations of FAP patients, where no collection of blood samples was performed. Therefore, we could not analyze blood levels of neurohormones in this study.

\section{CONCLUSIONS}

Analyses of the BP reaction after tilt reversal may be a marker to assess autonomic nervous dysfunction in FAP patients. Moreover, BP analyses do not require ECG recordings and analyses of HRV, an important finding, as heart arrhythmia often prevents evaluation of cardiac autonomic dysfunction in FAP patients. In addition, assessment of the post-tilt BP reaction points to possible treatment modalities for orthostatic hypotension at least in the early stages of the FAP disease.

\section{ABBREVIATIONS}

FAP, familial amyloidotic polyneuropathy; ATTR, amyloidogenic transthyretin; Val30Met, Valine30Methionine; BP, blood pressure; HR, heart rate; HRV, heart rate variability; $\mathrm{HF}$, high frequency; $\mathrm{LF}$, low frequency; $\mathrm{P}_{\text {tot }}$, total spectral power of heart rate; $\mathrm{P}_{\mathrm{LF}}$, power of the low frequency component; $\mathrm{P}_{\mathrm{HF}}$, power of the high frequency component; $\mathrm{P}_{\mathrm{LF}} / \mathrm{P}_{\mathrm{HF}}$ ratio between the power of the LF and HF components; ECG, electrocardiogram; PAF, pure autonomic failure; MSA, multiple system atrophy.

\section{ACKNOWLEDGEMENTS}

This study was supported by grants from the patient organization FAMY Västerbotten, FAMY/AMYL Norrbotten, and the Swedish Research Council (OBS) 10866-42062-34, and the EU Euramy Project.

1 Dwulet FE, Benson MD. Polymorphism of human plasma thyroxin binding prealbumin. Biochem Biophys Res Commun 1983; 114: 657-662.

2 Araki S. Type I familial amyloidotic polyneuropathy (Japanese type). Brain Dev 1984; 6: 128-133.

3 Tawara S, Nakazato M, Kangawa K, Matsuo H, Araki S. Identification of amyloid prealbumin variant in familial amyloidotic polyneuropathy (Japanese type). Biochem Biophys Res Commun 1983; 116: 880-888.

4 Ando Y, Suhr O. Autonomic dysfunction in familial amyloidotic polyneuropathy. Amyloid 1998; 5: 288-300.

5 Delahaye N, Le Guludec D, Dinanian S, Delforge J, Slama MS, Sarda L, Dollé F, Mzabi H, Samuel D, Adams D, Syrota A, Merlet P. Myocardial muscarinic receptor upregulation and normal response to isoproterenol in denervated hearts by familial amyloid polyneuropathy. Circulation 2001; 104: 2911-2916.

6 Kinoshita O, Hongo M, Saikawa Y, Katsuyama T, Tanaka M, Takeda M, Yamamoto H, Isobe M, Sekiguchi M. Heart rate variability in patients with familial amyloid polyneuropathy. Pacing Clin Electrophysiol 1997; 20: 2949-2953.

7 Morelli S, Carmenini E, Sgreccia A, Francia A. Heart rate variability and familial amyloidosis. Int J Cardiol 2002; 83: 295-297.

8 Olofsson BO, Suhr O, Niklasson U, Wiklund U, Bjerle P, Beckman A. Assessment of autonomic nerve function in familial amyloidotic polyneuropathy-a clinical study based of spectral analysis of heart rate variability. Amyloid 1994; 1: 240-246.

9 Wiklund U, Hörnsten R, Karlsson M, Suhr OB, Jensen SM. Abnormal heart rate variability and subtle atrial arrhythmia in patients with familial amyloidotic polyneuropathy. Ann Noninvasive Electrocardiol 2008; 13: 249-256.

10 Asahina M, Young TM, Bleasdale-Barr K, Mathias CJ. Differences in overshoot of blood pressure after head-up tilt in two groups with chronic autonomic failure: pure autonomic failure and multiple system atrophy. J Neurol 2005; 252: 72-77.

11 Chandler MP, Mathias CJ. Haemodynamic responses during head-up tilt and tilt reversal in two groups with chronic autonomic failure: pure autonomic failure and multiple system atrophy. J Neurol 2002; 249: 542-548.

12 Kario K, Shimada K, Schwartz JE, Matsuo T, Hoshide S, Pickering TG. Silent and clinically overt stroke in older Japanese subjects with white-coat and sustained hypertension. J Am Coll Cardiol 2001; 38: 238-245.

13 Young TM, Asahina M, Watson L, Mathias CJ. Hemodynamic effects of clonidine in two contrasting models of autonomic failure: multiple system atrophy and pure autonomic failure. Mov Disord 2006; 21: 609-615.

14 Okajima T, Nagata J, Hatamoto K, Kinoshita Y, Takaba Y, Tokuomi H. Pharmacological studies of the pupils in familial amyloid polyneuropathy. Ann Neurol 1978; 4: 80-84.

15 Takahashi K, Yi S, Kimura Y, Araki S. Familial amyloidotic polyneuropathy type 1 in Kumamoto, Japan: a clinicopathologic, histochemical, immunohistochemical, and ultrastructural study. Hum Pathol 1991; 22: 519-527. 
16 Sousa A, Andersson R, Drugge U, Holmgren G, Sandgren O. Familial amyloidotic polyneuropathy in Sweden: geographical distribution, age of onset, and prevalence. Hum Hered 1993; 43: 288-294.

17 Sousa A, Coelho T, Barros J, Sequeiros J. Genetic epidemiology of familial amyloidotic polyneuropathy (FAP)-type I in Póvoa do Varzim and Vila do Conde (north of Portugal). Am J Med Genet 1995; 60: 512-521.

18 Ando Y, Nakamura M, Araki S. Transthyretin-related familial amyloidotic polyneuropathy. Arch Neurol 2005; 62: 1057-1062.

19 Hörnsten R, Pennlert J, Wiklund U, Lindqvist P, Jensen SM, Suhr OB. Heart complications in familial transthyretin amyloidosis: impact of age and gender. Amyloid Amyloid 2010; 17: 63-68.

20 Suhr OB, Herlenius G, Friman S, Ericzon BG. Liver transplantation for hereditary transthyretin amyloidosis. Liver Transp/ 2000; 6: 263-276.

21 Wieling W, Van Lieshout JJ, Ten Harkel AD. Dynamics of circulatory adjustments to head-up tilt and tilt-back in healthy and sympathetically denervation subjects. Clin Sci (Lond) 1998; 94: 347-352.

22 Bergfeldt BL, Olofsson BO, Edhag KO. Electrophysiologic evaluation of the cardiac conduction system and its autonomic regulation in familial amyloid polyneuropathy. Am J Cardiol 1985; 56: 647-652.

23 Carvalho MJ, van Den Meiracker AH, Boomsma F, Lima M, Freitas J, Veld AJ, Falcao De Freitas A. Diurnal blood pressure variation in progressive autonomic failure. Hypertension 2000; 35: 892-897.
24 Kario K. Orthostatic hypertension: a measure of blood pressure variation for predicting cardiovascular risk. Circ J 2009; 73: 1002-1007.

25 Ando Y, Yamashita T, Tanaka Y, Tashima K, Yonehara T, Gotoh T, Sakashita N, Uchino $M$, Ando M. Role of nitric oxide in the peripheral vessels of patients with familial amyloidotic polyneuropathy (FAP) type I. J Auton Nerv Syst 1994; 50: 79-85.

26 Obayashi K, Ando Y, Nakamura M, Terazaki H, Yamashita T, Tashima K, Suga M, Uchino $\mathrm{M}$, Ando M. Endothelium-dependent vasodilatation in patients with familial amyloidotic polyneuropathy. Muscle Nerve 2000; 23: 1084-1088.

27 Beckman A, Bjerle P, Olofsson B. Electrocardiographic findings in familial amyloidotic polyneuropathy. Am J Noninvas Cardiol 1992; 6: 192-196.

28 Hörnsten R, Wiklund U, Olofsson BO, Jensen SM, Suhr OB. Liver transplantation does not prevent the development of life-threatening arrhythmia in familial amyloidotic polyneuropathy, Portuguese-type (ATTR Val30Met) patients. Transplantation 2004; 78: 112-116.

29 Yamamoto N, Sasaki E, Goda K, Nagata K, Tanaka H, Terasaki J, Yasuda H, Imagawa A, Hanafusa T. Treatment of post-dialytic orthostatic hypotension with an inflatable abdominal band in hemodialysis patients. Kidney Int 2006; 70: 1793-1800.

30 Gamboa A, Shibao C, Diedrich A, Paranjape SY, Farley G, Christman B, Raj SR, Robertson D, Biaggioni I. Excessive nitric oxide function and blood pressure regulation in patients with autonomic failure. Hypertension 2008; 51: 1531-1536.

31 Imholz BP, Wieling W, van Montfrans GA, Wesseling KH. Fifteen years experience with finger arterial pressure monitoring: assessment of the technology. Cardiovasc Res 1998; 38: 605-616. 